these weaknesses. The United States, which had not been one of the 6 members of the drafting group and which claimed it was having difficulty in getting its views considered, was particularly severe in its strictures that the report lacked 'soul'. As one of its delegates put it, "we have put a big effort into this conference; how can we defend this document to our scientists and technologists back home?" The British, too, were voicing concern both publicly and privately that "with all the expertise here in Vienna" nothing more helpful was emerging for consideration in planning future development programmes.

Certainly much of the document merely repeated the same general principles as were being negotiated more formally in the Programme of Action elsewhere. But by this stage there was not enough time left to start again from scratch. Nor would many developing country representatives have been pleased at the prospect, as they were more in need of a general statement of principles to put to the government back home rather than a 'soulful' document.

In the event, and amidst much lobbying by the US, a second draft was produced which left the Americans moderately satisfied without causing problems amongst developing countries. Some of the key points are outlined below.

Science: 'Science policy should be mainly linked to long term objectives'. 'Science and technology ... . should be consistent with national aspirations and objectives'. 'Science of the future must include in its concerns the uplifting of the welfare of the total human being' (the first version had contained the phrase "basic science should be left free to follow its own internal dynamics').

Obstacles: 'One of the most urgent questions is disarmament . . . more effect should be given to analysing in what ways ongoing research and technical application now directed towards war could be adjusted for peaceful applications'. 'The brain drain of the most skilful scientists and technologists from developing countries creates a serious obstacle to their own scientific and technological development ... . developed countries should assist by actively discouraging a brain drain from developing countries'. This last phrase was concocted as an alternative to the more loaded phrase 'should assist by not enticing scientists and technologists from developing countries', to which some developed countries took exception. But at least one delegate was wondering privately whether 'discouraging' the brain drain did not contravene agreements on the free-flow of scientists.

The United States would additionally have liked a reference to the population problem, but could not get a consensus.

Objectives: 'All countries should develop

\title{
G77 wins on global information network
}

ONE of the few victories of UNCSTD, from the point of view of the developing countries, is the agreement in principle to set up a global information system for the benefit of the Third World. This was a hard-fought victory, with resistance from the US, Canada, Japan and the EEC. And it is a victory that also places responsibility on the developing countries to evolve extensive national systems.

The developed countries had argued that systems which operate with such low efficiency in the developed world, with all possible sophisticated backup, have little chance of operating efficiently in the third world. But after what amounted to the Group of 77's toughest stand at UNCSTD, the developed countries agreed to develop a global information system within the United Nations system, having a global focal-point and series of networks including national focal points.

The function of the global focal-point caused much controversy. The developing countries wanted to perform both retrieval and referral functions. The developed countries believed it was not technically possible for the global-point to perform a retrieval function.

After four days of negotiation in closed committee meetings, the Group of 77 finally dropped its demand. It was decided that the focal point will perform the referral function, but will also act as a

endogenous capabilities to assess the trends of science and the consequences of technological options'. 'Developing countries have to carry out their own studies of global problems so as to bring their own perspective to bear on the world problematique.' 'Goals include overcoming poverty and seeking ways to reduce the disparities that exist between developed and developing societies in, for example, life expectancy, infant mortality and education'. A stronger version speaking of 'halving by the year 2000 the disparities' could not attract a consensus.

Resources: 'As concerns R and D activities in developing countries, every effort should be made by the world community to raise the level of these activities from the present very low level to a substantially increased level. It was the considered view of many delegations that a more quantitative goal should be set and they felt that this should be of the order of $20 \%$ to $25 \%$ of global world research and development expenditure by the year 2000 '. Countries such as India and Bangladesh were keen to have a target, but there were doubts amongst some countries about the reasonableness of these targets or even the precise definition of the terms used.

Action: The building up of endogenous capabilities requires 'massive expansion of "complaints bureau". The retrieval function will be performed largely by the national focal points, but users facing difficulties in getting a response would be able to refer to the global focal-point.

For the global information network to function properly, the national focalpoints must provide significant backup support. The Third World countries are required to extend and develop their national information systems considerably, and to have storage and retrieval facilities on information concerning development of science and technology, foreign sources of technology supply, sources of foreign capital and their conditions, and national users of science and technology. In their turn, the developed countries would extend their own facilities for use by developing countries. They also agreed to provide, "the fullest possible access to available information technologies".

Furthermore, the developed countries would allow access to research and development information relevant to the social and economic development of developing countries"'. Who decides what is relevant and what are the criteria of relevancy, however, were not significantly discussed. Also omitted. from the general agreement is the question of confidentiality.

ZIAUDDIN SARDAR

the educational system in order to provide access to primary, secondary, technical and higher education to most, if not all, the populations, male and female equally'.

Governments in developing countries should provide support both for existing and new centres of excellence "dedicated to both basic research and applied research of relevance to their societies'.

Scientists in developed countries 'should be encouraged and helped by their governments to take a more active interest in solving problems in developing countries exchange of scientists and technologists between developed and developing countries should be encouraged

informal communications between scientists based on mutual interest are also among the powerful instruments which can be used to help in problem solving'.

Specifics: The working group made sure, in a footnote, that just about every branch of science and technology with the remotest relevance to development received a mention. But it also identified in the main text some rapidly developing fields such as information technology, nonconventional generation of energy (including fusion), biotechnologies and marine sciences.

Women and young scientists: 'Technological development often affects men and women differently and the intro- 